\title{
Influence of shallowness, bank inclination and bank roughness on the variability of flow patterns and boundary shear stress due to secondary currents in straight open-channels
}

\author{
K. Blanckaert ${ }^{\mathrm{a}, \mathrm{b}, *}$, A. Duarte ${ }^{\mathrm{a}}$, A.J. Schleiss ${ }^{\mathrm{a}}$ \\ a Laboratory of Hydraulic Constructions (LCH-ENAC), Ecole Polytechnique Fédérale Lausanne (EPFL), Switzerland \\ b State Key Laboratory of Urban and Regional Ecology, Research Center for Eco-Environmental Sciences (RCEES), Chinese Academy of Sciences (CAS), Beijing, China
}

\section{A R T I C L E I N F O}

\section{Article history:}

Received 11 February 2010

Received in revised form 16 June 2010

Accepted 17 June 2010

Available online 23 June 2010

\section{Keywords:}

Bank inclination

Boundary roughness

Velocity patterns

Secondary current

Boundary shear stress

Flow variability

\begin{abstract}
A B S T R A C T
Boundary shear stress and flow variability due to its interaction with main flow and secondary currents were investigated under conditions that extend previous research on trapezoidal channels. Secondary currents that scale with the flow depth were found over the entire width in all experiments. These findings contradict the widespread perception that secondary currents die out at a distance of 2.5 times the flow depth from the bank, a perception which is largely based on experiments with smooth boundaries. The reported results indicate that a stable pattern of secondary currents over the entire channel width can only be sustained over a fixed horizontal bed if the bed's roughness is sufficient to provide the required transverse oscillations in the turbulent shear stresses. Contrary to laboratory flumes, alluvial river bed always provide sufficient roughness. The required external forcing of this hydrodynamic instability mechanism is provided by the turbulence-generated near-bank secondary currents. The pattern of near-bank secondary currents depends on the inclination and the roughness of the bank. In all configurations, secondary currents result in a reduction of the bed shear stress in the vicinity of the bank and a heterogeneous bank shear stress that reaches a maximum close to the toe of the bank. Moreover, these currents cause transverse variability of $10-15 \%$ for the streamwise velocities and $0.2 u_{*}^{2}-0.3 u_{*}^{2}$ for the bed shear stress. These variations are insufficient to provide the flow variability required in river restoration projects, but nevertheless must be accounted for in the design of stable channels.
\end{abstract}

(c) 2010 Elsevier Ltd. All rights reserved.

\section{Introduction}

The boundary shear stress in open-channel flows quantifies the resistance to the flow, determines the conveyance capacity, and provokes sediment transport. Hydraulic variability and erosion and sedimentation variability is often caused by the interaction of the main flow, the secondary currents, the turbulence characteristics, the boundary shear stress, the sediment transport and the mobile boundaries. Accurate predictions of the boundary shear stress and its variability are thus important for design of stable channels, analysis and design of river and ecosystem rehabilitation, mitigation of hazards and prediction of river morphodynamics. Examples of practical relevance can be found in all regions of the world: e.g. the Spree river in Berlin, the Haihe River in Beijing or the Los Angeles River in California.

Van Balen et al. [31,32] investigated the hydrodynamics of openchannel flow with horizontal bed topography [31] and with a naturallike bed topography deformed by the flow [32]. Their basis for analysis

\footnotetext{
* Corresponding author.

E-mail address: koen.blanckaert@epfl.ch (K. Blanckaert).
}

was the comparison of data from experiments, large eddy simulations (LES) and Reynolds averaged numerical simulations (RANS). In configurations with horizontal beds, they found that important flow processes and variables such as near-bank secondary currents, internal shear layers, turbulent kinetic energy and boundary shear stresses are conditioned by the structure of the turbulence. These processes and variables could only be accurately resolved by means of LES models. However, for configurations with pseudo-natural deformed bed topography, there was hardly any difference between LES and RANS simulations, indicating that the hydrodynamics are largely conditioned by the bed topography and that turbulence only plays a minor role. These results are in line with those produced by Zeng et al.'s [37] numerical study and Blanckaert [3] experimental study, and suggest that the hydrodynamics in trapezoidal channels are far more complicated than those in irregular geometries. Trapezoidal channels are thus an appropriate and very demanding configuration for the investigation of boundary shear stress and the variability. This configuration is also very relevant to practice, as trapezoidal channels are important in river engineering and management. Examples include the channelization of rivers in urbanized areas and the design of irrigation channels. 
In engineering practice it is still common to adopt the boundary shear stress distribution proposed by Chow ([7], Fig. 1) for flow in straight trapezoidal channels with uniform boundary roughness. Knight et al. [15], Knight and Patel [14] and Knight et al. [16,17] investigated the boundary shear stress in smooth as well as in roughened trapezoidal channels with banks that have larger roughness values than the bed. Based on laboratory measurements of the boundary shear stress with a Prandtl tube they proposed two equations. The first is for the ratio of the shear force carried by the bed and the banks. The second equation calculates the mean and maximum shear stresses on the bed and the banks as a function of channel geometry and the ratio of the bank roughness to the bed roughness.

Although these researchers recognized the importance of secondary currents with respect to the heterogeneity of the boundary shear stress distribution, they were not able to measure these currents or to reveal the underlying physical mechanisms. In spite of secondary currents' low energy content - their maximum velocities are typically about $2 \%$ of the main velocity [23] - they are known to be efficient in advecting momentum, and thereby in altering the patterns of velocity, boundary shear stress, turbulence and sediment transport. They have a size that typically scales with the flow depth and are commonly referred to as secondary currents of Prandtl's [26] second kind because they are induced by turbulence [23].

A widespread theory of secondary currents in straight open-channel flows over flat stable beds with uniform roughness is that they are generated by bank effects and die out at a distance of 2.5 times the flow depth from the bank (e.g. $[23,29])$. The observation of secondary current over the entire width in wide and shallow natural rivers $[12,13,23,25,33]$ is attributed to a positive feedback between flow and sediment transport, which leads to a non-uniform bed roughness. This widespread theory is in line with laboratory experiments with longitudinal roughness strips $[19,22,23,28,34,35]$ that result in secondary currents over the entire width in wide channels. Ikeda [11] was the first to argue that the basic mechanism causing the formation of secondary currents over the entire width is the interaction between flow and sediment transport. Ikeda proposed that this interaction leads to the formation of longitudinal ridges (deposits of sediment in regions of ascending vertical velocities induced by the secondary currents) and the stabilization of secondary currents in the central part of the channel. Colombini [8] added theoretical development to Ikeda's work. This widespread theory is largely based on laboratory experiments in smooth air ducts by Nezu et al. [24].

The theory is contradicted, however, by recent laboratory experiments in configurations with immobile uniformly rough bed and smooth banks by Rodrígues and Gárcia [27] and Albayrak [1]. These experiments show the existence of secondary currents over the entire width of the channel. For the case of their relatively narrow channels with width-to-depth ratios of 6.3 and 8.5, Rodrígues and Gárcia [27] speculate that the difference between the bed and the bank roughness strengthens the corner surface vortex, which may compensate for the expected decay of the secondary currents with distance from the bank. However, it is questionable whether this mechanism could explain the secondary currents present over the entire width of the

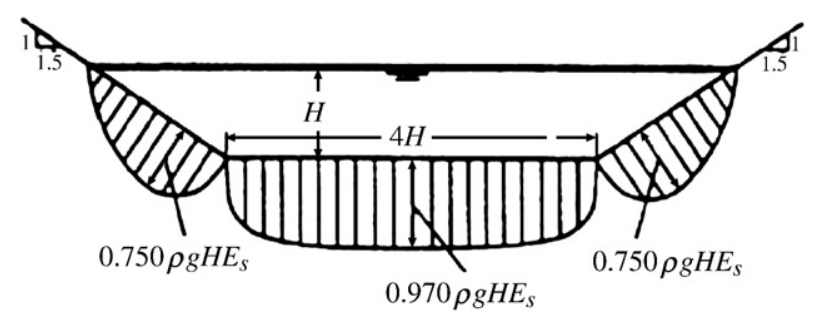

Fig. 1. Boundary shear stress distribution in smooth trapezoidal open-channels according to Chow [7]. Notations of the present paper have been adopted. $E_{s}$ represents the energy gradient. channel in Albayrak's [1] experiments with width-to-depth ratios of 12.3, 15 and 20. These observations of flows with rough beds and smooth banks suggest a strengthening of the secondary currents with increasing bed roughness, in line with previous experimental [29] and numerical work [20].

It has long been recognized that the roughness of the boundary, the difference in roughness between the bed and the banks, and the inclination of the banks have an important influence on the patterns of secondary currents and the boundary shear stress distribution. But the extent of such influences has only been partially addressed. Tominaga et al. [29] investigated the effects of: (i) the width-to-depth ratio $(2<B / H<8)$ in smooth and uniformly roughened rectangular channels; (ii) the width-to-depth ratio $(2<B / H<8)$ in smooth trapezoidal channels for bank inclinations of $32^{\circ}, 44^{\circ}$ and $60^{\circ}$; (iii) the width-to-depth ratio $(B / H=4,8)$ and differences between the bed and the bank roughness in rectangular channels with roughness on the entire perimeter, only on the bed and only on the bank, respectively. Their experiments showed that the width-to-depth ratio, the bank inclination and the roughness distribution have a notable effect on the strength and pattern of the secondary currents and on the shear stress distribution.

This paper reports and analyzes experiments in straight openchannel flows that complement previous experimental research by broadening the investigated range of shallowness (width-to-depth ratio), bank inclination and roughness of the bed and the banks, as well as combinations of these three parameters (Tables 1 and 2). Especially important for engineering practice are configurations that broaden towards shallower cross-sections and that have banks that are smoother (representing concrete banks) or rougher (representing riprap bank protection) than the bed. Moreover this paper complements previous experimental research by investigating with unprecedented detail the patterns of turbulent stresses and turbulent kinetic energy as well as their relation to the patterns of secondary currents. An additional objective of this paper is to provide detailed experimental data under various hydraulic and geometric conditions. This data is provided with the hope that it will lead to progress in the understanding and modeling of the interactions between main flow, secondary currents, turbulence characteristics and boundary shear stress.

Section 2 presents the experimental set-up. Section 3 focuses on the influence of shallowness on patterns of flow and bed shear stress, touching especially on the question of whether secondary currents can exist over the entire width of shallow channels with immobile uniformly rough bed. This section also investigates the linkages between these turbulence-induced secondary currents and several turbulence characteristics. Section 4 analyzes the influence of bank inclination and bank roughness on the patterns of secondary currents, velocity distributions and bed and bank shear stress. Section 5 discusses the new insights provided by the experimental observations. This section focuses on the mechanisms generating secondary currents, as well as on the interaction between the secondary currents in the central part of the cross-section and those near the banks. Additionally, it evaluates the empirical boundary shear stress estimations of Chow [7] and Knight et al. [16,17].

\section{Experimental set-up}

Laboratory experiments were carried out in a $1.3 \mathrm{~m}$ wide laboratory flume with a $9 \mathrm{~m}$ long straight reach (Fig. 2). Detailed information on the hydraulic and geometric conditions is given in Tables 1 and 2. All experiments were carried out under similar hydraulic conditions with an overall velocity of $U=Q$ / $(B H) \sim 0.4 \mathrm{~ms}^{-1} ; \mathrm{Q}$ is the flow discharge, $H$ is the flow depth and $B$ is the average of the width at the bed and at the water surface. Experiments on the influence of the flow shallowness were carried out with flow depths of $0.11 \mathrm{~m}, 0.16 \mathrm{~m}$ and $0.21 \mathrm{~m}$, whereas 
Table 1

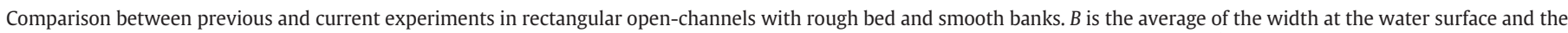

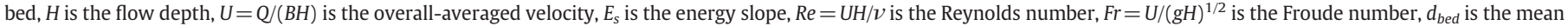
diameter of the bed material, and $R e^{*}=u * d / \nu$ is the Reynolds particle number based on the shear velocity $u^{*}=\left(g R_{h} E_{S}\right)^{1 / 2}$ and the hydraulic radius $R_{h}$.

\begin{tabular}{|c|c|c|c|c|c|c|c|c|c|}
\hline References & $\begin{array}{l}B \\
{[\mathrm{~m}]}\end{array}$ & $\begin{array}{l}B / H \\
{[-]}\end{array}$ & $\begin{array}{l}U \\
{\left[\mathrm{~ms}^{-1}\right]}\end{array}$ & $\begin{array}{l}E_{s} \\
{\left[10^{-4}\right]}\end{array}$ & $\begin{array}{l}\operatorname{Re}=U H / \nu \\
{\left[10^{3}\right]}\end{array}$ & $\begin{array}{l}F r=U /(g H)^{1 / 2} \\
{[-]}\end{array}$ & $\begin{array}{l}d_{\text {bed }} \\
{[\mathrm{mm}]}\end{array}$ & $\begin{array}{l}d_{\text {bed }} / H \\
{[-]}\end{array}$ & $\begin{array}{l}R e^{*}=u * d / \nu \\
{[-]}\end{array}$ \\
\hline \multicolumn{10}{|l|}{ Tominaga et al. [29] } \\
\hline Exp. R22 & 0.40 & 4.0 & 0.35 & 10.6 & 35 & 0.35 & 12 & 0.12 & 317 \\
\hline Exp. R21 & 0.40 & 8.0 & 0.35 & 34.1 & 18 & 0.51 & 12 & 0.24 & 439 \\
\hline \multicolumn{10}{|l|}{ Nezu et al. [25] } \\
\hline Biwako Soui River & 17.50 & 8.0 & 0.36 & NA & 800 & 0.08 & NA & NA & NA \\
\hline \multicolumn{10}{|c|}{ Rodrígues and Gárcia [27] } \\
\hline Exp. FB2 & 0.91 & 6.3 & 0.72 & 25 & 82 & 0.60 & 10 & 0.07 & 530 \\
\hline Exp. FB1 & 0.91 & 8.5 & 0.48 & 25 & 44 & 0.45 & 10 & 0.09 & 470 \\
\hline \multicolumn{10}{|l|}{ Albayrak [1] } \\
\hline Exp. S3 & 2.40 & 12.3 & 0.15 & 0.5 & 30 & 0.11 & 15 & 0.077 & 146 \\
\hline Exp. S1 & 2.40 & 12.3 & 0.39 & 4.2 & 77 & 0.29 & 15 & 0.077 & 425 \\
\hline Exp. S2 & 2.40 & 12.3 & 0.55 & 9.1 & 107 & 0.40 & 15 & 0.077 & 627 \\
\hline Exp. S4 & 2.40 & 15.0 & 0.43 & 6.6 & 69 & 0.34 & 15 & 0.094 & 483 \\
\hline Exp. S5 & 2.40 & 15.0 & 0.50 & 7.5 & 80 & 0.40 & 15 & 0.094 & 513 \\
\hline Exp. S6 & 2.40 & 20.0 & 0.36 & 6.0 & 44 & 0.33 & 15 & 0.125 & 398 \\
\hline \multicolumn{10}{|l|}{ Present paper } \\
\hline Exp. F21_90_00 & 1.30 & 6.2 & 0.38 & 4.1 & 80 & 0.27 & 2 & 0.010 & 51 \\
\hline Exp. F16_90_00 & 1.30 & 8.1 & 0.43 & 6.2 & 69 & 0.34 & 2 & 0.013 & 56 \\
\hline Exp. F11_90_00 & 1.30 & 11.9 & 0.40 & 6.8 & 44 & 0.39 & 2 & 0.018 & 50 \\
\hline
\end{tabular}

experiments on the influence of the bank inclination and roughness were carried out with a flow depth of $0.16 \mathrm{~m}$. For all configurations, the right bank (at the left in the figures) was smooth and vertical in order to maximize the shallowness. This design enabled investigation of the hypothesis that secondary currents die out at a distance of 2.5 times the flow depth from the banks (see the $B / H$ values in Tables 1 and 2 ). The flat bed, composed of quasi-uniform sand grains with a diameter of $d=2 \mathrm{~mm}$, was immobilized by means of paint. The experiments are labeled according to their major parameters. The experiment F11_45_30, for example was performed over a flat $(F)$ bed with a flow depth of $0.11 \mathrm{~m}$, an inclination of the left bank of $45^{\circ}$ and an equivalent sand roughness of the left bank of $30 \mathrm{~mm}$.

Measurements of the bed and the water surface topography were made by moving a set of 8 echosounders mounted on a carriage along the flume (cf. Fig. 2) on a grid of $0.1 \mathrm{~m}$ by $0.1 \mathrm{~m}$. The uncertainty in these measurements was estimated to be less than $1 \mathrm{~mm}$. The discharge was measured with an uncertainty of less than $5 \%$ with an electromagnetic flow meter installed on the supply pipe. Non-intrusive measurements of at least 36 vertical profiles were carried out in the cross-section at $6.5 \mathrm{~m}$ from the flume's entrance with an Acoustic Doppler Velocity Profiler (ADVP, cf. Fig. 2), which simultaneously measures profiles of the three velocity components. The working principle of the ADVP has been reported by Lemmin and Rolland [18], Hurther and Lemmin [10], Blanckaert and Graf [5] and Blanckaert and Lemmin [6]. The $(s, n, z)$ reference system is defined in Fig. 2. Measurements were carried out at a frequency of $31.25 \mathrm{~Hz}$ during $180 \mathrm{~s}$, which guarantees reliable estimates of the mean velocities and the Reynolds stresses. The profiling capacity of the ADVP allows measurements with a high spatial resolution (cf. Fig. 2) that enables accurately resolving the patterns of the weak secondary currents. Blanckaert [3] reports detailed information on the adopted ADVP configurations and the data treatment procedures and estimates the uncertainty in the streamwise velocity component $v_{s}$ at $4 \%$, in the cross-stream velocities $\left(v_{n}, v_{z}\right)$ at $10 \%$, in the turbulent shear stresses $\overline{v_{s}^{\prime} v_{n}^{\prime}}$ and $\overline{v_{s}^{\prime} v_{z}^{\prime}}$ at 15\%, in the turbulent kinetic energy tke at $20 \%$ and in the streamfunction $\psi$ of the secondary currents at $20 \%$. For

Table 2

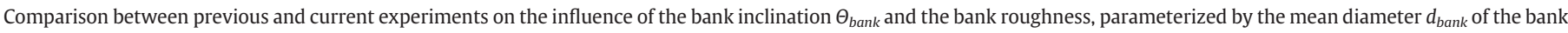
material. The other variables are defined in the caption of Table 1.

\begin{tabular}{|c|c|c|c|c|c|c|c|c|c|c|c|}
\hline References & $\begin{array}{l}B \\
{[\mathrm{~m}]}\end{array}$ & $\begin{array}{l}B / H \\
{[-]}\end{array}$ & $\begin{array}{l}U \\
{\left[\mathrm{~ms}^{-1}\right]}\end{array}$ & $\begin{array}{l}E_{s} \\
{\left[10^{-4}\right]}\end{array}$ & $\begin{array}{l}\operatorname{Re}=U H / \nu \\
{\left[10^{3}\right]}\end{array}$ & $\begin{array}{l}F r=U /(g H)^{1 / 2} \\
{[-]}\end{array}$ & $\begin{array}{l}d_{\text {bank }} \\
{[\mathrm{mm}]}\end{array}$ & $\begin{array}{l}d_{b e d} \\
{[\mathrm{~mm}]}\end{array}$ & $\begin{array}{l}d_{\text {bed }} / H \\
{[-]}\end{array}$ & $\begin{array}{l}R e_{*}=u * d / \nu \\
{[-]}\end{array}$ & $\begin{array}{l}\Theta_{\text {bank }} \\
{\left[{ }^{\circ}\right]}\end{array}$ \\
\hline \multicolumn{12}{|l|}{ Tominaga et al. [29] } \\
\hline \multicolumn{12}{|l|}{ Rectangular channel } \\
\hline Exp. S1 & 0.40 & 8.0 & 0.40 & 9.4 & 20 & 0.57 & NA & NA & NA & $<5$ & 90 \\
\hline Exp. R11 & 0.32 & 7.9 & 0.37 & 52.2 & 15 & 0.59 & 12 & 12 & 0.30 & 485 & 90 \\
\hline Exp. R21 & 0.40 & 8.0 & 0.35 & 34.1 & 18 & 0.51 & NA & 12 & 0.24 & 439 & 90 \\
\hline Exp. R31 & 0.32 & 7.9 & 0.33 & 12.5 & 13 & 0.52 & 12 & NA & NA & $<5$ & 90 \\
\hline \multicolumn{12}{|l|}{ Tominaga et al. [29] } \\
\hline \multicolumn{12}{|l|}{ Trapezoidal channel } \\
\hline Exp. T11 & 0.27 & 8.5 & 0.32 & NA & 10 & 0.58 & NA & NA & NA & $<5$ & 60 \\
\hline Exp. T01 & 0.24 & 7.6 & 0.35 & 13.8 & 11 & 0.64 & NA & NA & NA & $<5$ & 44 \\
\hline Exp. T03 & 0.29 & 3.3 & 0.37 & 5.9 & 34 & 0.40 & NA & NA & NA & $<5$ & 44 \\
\hline Exp. T22 & 0.22 & 5.4 & 0.37 & NA & 15 & 0.59 & NA & NA & NA & $<5$ & 32 \\
\hline Exp. T23 & 0.28 & 3.7 & 0.33 & 5.9 & 23 & 0.40 & NA & NA & NA & $<5$ & 32 \\
\hline \multicolumn{12}{|l|}{ Present paper } \\
\hline Exp. F16_90_00 & 1.30 & 8.1 & 0.43 & 6.2 & 69 & 0.34 & NA & 2 & 0.013 & 56 & 90 \\
\hline Exp. F16_45_00 & 1.22 & 7.6 & 0.43 & 6.2 & 69 & 0.34 & NA & 2 & 0.013 & 56 & 45 \\
\hline Exp. F16_45_02 & 1.22 & 7.6 & 0.43 & 6.7 & 69 & 0.34 & 2 & 2 & 0.013 & 58 & 45 \\
\hline Exp. F11_45_30 & 1.22 & 7.6 & 0.44 & 8.7 & 70 & 0.35 & 30 & 2 & 0.013 & 66 & 45 \\
\hline Exp. F16_30_00 & 1.16 & 7.1 & 0.43 & 5.5 & 69 & 0.34 & NA & 2 & 0.013 & 52 & 30 \\
\hline Exp. F16_30_02 & 1.16 & 7.1 & 0.43 & 5.9 & 69 & 0.34 & 2 & 2 & 0.013 & 54 & 30 \\
\hline Exp. F11_30_30 & 1.16 & 7.1 & 0.43 & 7.6 & 69 & 0.34 & 30 & 2 & 0.013 & 61 & 30 \\
\hline
\end{tabular}



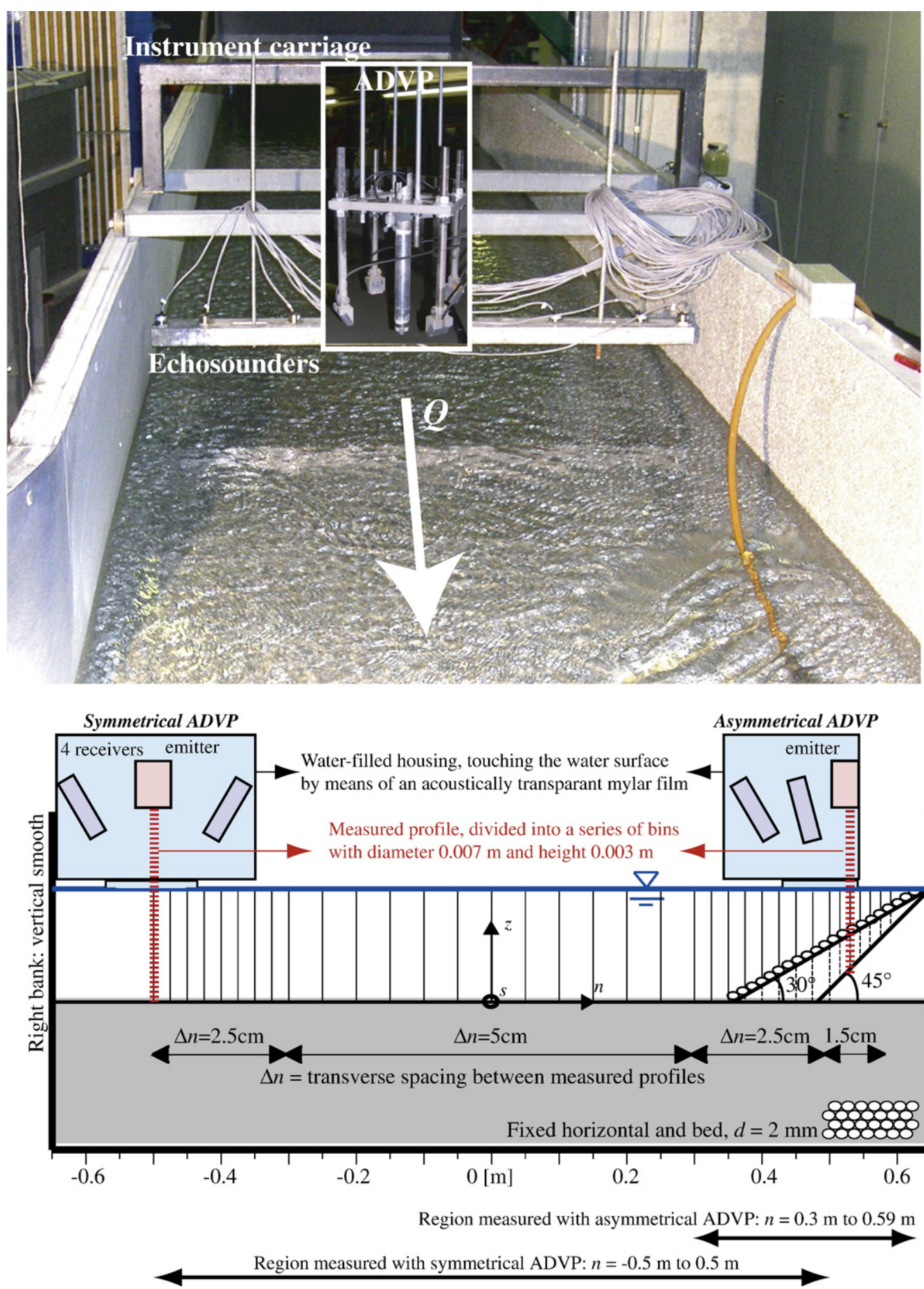

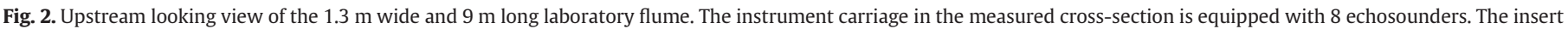
shows the ADVP transducers. The scheme defines the references axis, the measuring grid and the adopted ADVP configurations.

variables characterized by small values ( $\operatorname{such}$ as $v_{n}, v_{z}, \psi, \overline{v_{s}^{\prime} v_{n}^{\prime}}$ ), these relative errors are defined with respect to the average magnitude of the variable in the flow domain. The streamfunction $\psi$ is computed as [2]:

$\psi(n, z)=\int_{z_{\text {bed }}}^{z} v_{n} d z$

This scalar variable parameterizes and visualizes well the patterns of secondary currents. The bank shear stress is estimated by fitting a logarithmic profile to the measured velocities in the lowest part of a profile perpendicular to the bank, similar to Tominaga et al. [29] and Nezu and Nakagawa [23]. This procedure is further discussed in Duarte [9], who estimates the uncertainty in this procedure at $20 \%$. The bed shear stress can be obtained with a lower uncertainty of about $10 \%$ from the depth-averaged velocity $U_{s}$ as:

$\tau_{\text {bed }}=\rho C_{f, b e d} U_{s}^{2}$.

The bed roughness is constant in the investigated experiments with fixed horizontal bed, and thus it can reliably be assumed that the Chézy friction coefficient $C_{f, \text { bed }}$ is approximately constant. The 
dimensionless Chézy coefficient for the sand bed, $C_{f, b e d}=0.0053$, differs from the dimensionless Chézy coefficient for the entire crosssection, $C_{f}=g R_{h} E_{S} / U^{2}\left(R_{h}\right.$ is the hydraulic radius and $E_{s}$ is the energy slope, cf. Tables 1 and 2 ). As a result, the normalized bed shear stress is obtained as:

$\frac{\tau_{\text {bed }}}{\tau_{o}}=\left(\frac{C_{f, \text { bed }}}{C_{f}}\right) \frac{U_{s}^{2}}{U^{2}}$

$\tau_{0}=\rho g R_{h} E_{s}$ is the cross-sectional averaged boundary shear stress.

\section{Influence of shallowness on patterns of flow and bed shear stress}

As mentioned before, laboratory experiments with smooth boundaries led to the widespread perception that secondary currents are generated at the banks and die out at a distance larger than $2.5 \mathrm{H}$ from the bank. This perception is contradicted by the existence of secondary currents over the entire width in laboratory experiments by Tominaga et al. [29], Rodrígues and Gárcia [27] and Albayrak [1] and in an irrigation channel by Nezu et al. [25]. The existence of these currents over the entire width has been attributed to the bed roughness. Our F11_90_00, F16_90_00 and F21_90_00 experiments complement and develop this previous research (cf. Table 1 ). They are characterized by a relatively small roughness $\left(R e^{*}=u * d / v \approx 50\right.$, which corresponds to the upper end of the transition region between smooth and rough turbulent boundary layer flow) and therefore fall between smooth boundary conditions $\left(R e_{*}<5\right)$ and the notably rougher conditions investigated by Tominaga et al. [29], Rodrígues and Gárcia [27] and Albayrak [1]. Moreover, the investigated widthto-depth ratios are similar to that of the irrigation channel investigated by Nezu et al. [25], and fall between the narrow configurations investigated by Tominaga et al. [29] and Rodrígues and Gárcia [27] and the relatively shallow cross-sections investigated by Albayrak [1].

The secondary currents are weak, with maximum cross-stream velocities of about $2 \%$ of the main velocity, $\left(v_{n}, v_{z}\right)_{\max } / U=0.02$ (Figs. 3 , 4 and 5), which makes their definition and quantification difficult. A clear definition of the patterns of secondary currents is obtained only by simultaneously visualizing the patterns of the secondary currents illustrated by the streamfunction $\psi$, the cross-stream velocity components $\left(v_{n}, v_{z}\right)$, the streamwise velocity $v_{s}$ and the corresponding bed shear stress $\tau_{\text {bed }}=C_{f, \text { bed }} U_{s}^{2}$ (cf. Eq. (2)), the turbulent kinetic energy tke, and the turbulent shear stresses $\overline{v_{s}^{\prime} v_{n}^{\prime}}$ and $\overline{v_{s}^{\prime} v_{z}^{\prime}}$. Fig. 3 illustrates the patterns of these variables for the shallowest F11_90_00 experiment, whereas Figs. 4 and 5 illustrate the patterns of the major variables in the F16_90_00 and F21_90_00 experiments. Figs. 3(a), 4(a) and 5(a) schematically show the patterns of the secondary currents inferred from the patterns of these hydrodynamic variables. The indicated rotational sense of the secondary currents corresponds to the sign of the streamfunction $\psi$ (Figs. 3(b), 4(b) and 5 (b)), as well as the measured patterns of transverse and vertical velocities (Figs. 3(c, d), 4(c) and 5(c)). In all three experiments, secondary currents exist over the entire width of the cross-section. They are scaled with the flow depth, resulting in 6,8 and 12 circulation cells in the F21_90_00, F16_90_00 and F11_90_00 experiments, respectively. The secondary currents seem to weaken slightly with distance from the bank.

The patterns of all hydrodynamic variables are in total synchronicity with those of the secondary currents, indicating that advective momentum transport by the secondary currents determines the hydrodynamics. Zones of upflow/downflow coincide with zones of lower/higher streamwise velocity and corresponding boundary shear stress. The observed strength of the secondary currents and the magnitude of the transverse oscillations of $10 \%-15 \%$ in the stream- wise velocity (Figs. 3(e), 4(d) and 5(d)) and of $0.2 u^{2}-0.3 u^{2}$ in the bed shear stress (Figs. 3(f), 4(e) and (f)) are consistent with experimental results reported by Tominaga et al. [29], Nezu and Nakagawa [23], Rodrígues and Gárcia [27] and Albayrak [1] in laboratory flumes, and Nezu et al. [25] in the Biwako Sosui irrigation channel.

Our measurements with unprecedented spatial resolution allowed investigation of the linkage between the turbulence-induced secondary currents and some turbulence characteristics. As expected, advective transport of tke causes an increase/decrease of tke in zones of upflow/downflow (Fig. 3(g)). The difference in magnitude between zones of upflow and downflow is about $0.4 u^{2}$. More surprisingly, the pattern of secondary currents appears most clearly in the streamwise-transverse turbulent shear stress $\overline{v_{s}^{\prime} v_{n}^{\prime}}$ (Figs. 3(h), 4 (f) and 5(f)). Clockwise/counterclockwise rotating secondary currents correspond to negative/positive zones of $\overline{v_{s}^{\prime} v_{n}^{\prime}}$ that are quasihomogeneous over the flow depth. When modeled by means of an eddy viscosity, this turbulent shear stress relates to transverse gradients in the streamwise velocity, $\partial v_{s} / \partial n$. The secondary currents also considerably influence the vertical profiles of the streamwisevertical shear stress $\overline{v_{s}^{\prime} v_{z}^{\prime}}$ (Fig. 3(i)). In the absence of secondary currents, this shear stress would linearly evolve from 0 at the water surface to a maximum magnitude of $-\tau_{\text {bed }} / \rho$ ( $\rho$ is the density of the water) at the bed. The vertical profiles in zones of upflow are concave and reach a maximum value at about $z=0.3 \mathrm{H}$. Conversely, in zones of downflow these profiles are convex and increase more-than-linearly from the water surface to the bed. These observations are in agreement with Albayrak's [1] results. The difference in magnitude between zones of upflow and downflow is about $0.2 u^{2}$. These transverse oscillations of the turbulence characteristics affect both bed-load and suspended-matter transport.

Open-channel configurations are characterized by a "surface vortex" located above a counter-rotating "bottom vortex" in the corner formed by a vertical bank and a horizontal bed. This vortex system reveals the presence of velocities moving away from the bank at the water surface and the bed, and towards the bank at the junction of both vortices. Bank and bed roughness affect the relative strength of both vortices. Based on experiments in relatively narrow channels, Rodrígues and Gárcia [27] suggest that the bottom vortex dominates in configurations with uniform boundary roughness, whereas the surface vortex dominates in configurations with beds rougher than the bank. The dominant vortex drives the adjacent secondary current cell, which rotates in the opposite direction. The reported F11_90_00, F16_90_00 and F21_90_00 experiments confirm Rodrígues and Gárcia's [27] hypothesis (Figs. 3, 4 and 5). The surface vortex is the widest and strongest secondary current cell in the cross-section. Its width is slightly larger than the flow depth, and it clearly dominates the bottom vortex, as indicated by the rotational sense of the adjacent vortex.

\section{Influence of bank inclination and bank roughness on patterns of flow and boundary shear stress}

Tominaga et al. [29] investigated the effect of differentiated bank and bed roughness in channels with rectangular cross-section. They investigated homogeneous smooth and rough boundaries (their experiments S1 and R11, respectively, see Table 2), a rough bed combined with smooth banks (their experiment R21) and a smooth bed combined with rough banks (their experiment R31). Additionally, Tominaga et al. [29] investigated the effect of the inclination of the bank $\Theta_{\text {bank }}$ in smooth trapezoidal channels (their experiments T11, T01, T22, T3 and T23). Our experiments complement and extend this previous research, as summarized in Table 2. The shallowness is similar to that of Tominaga et al.'s [29] shallowest experiments. However, our investigation of the influence of the roughness of the bank and/or the bed is extended to trapezoidal channels, and our 


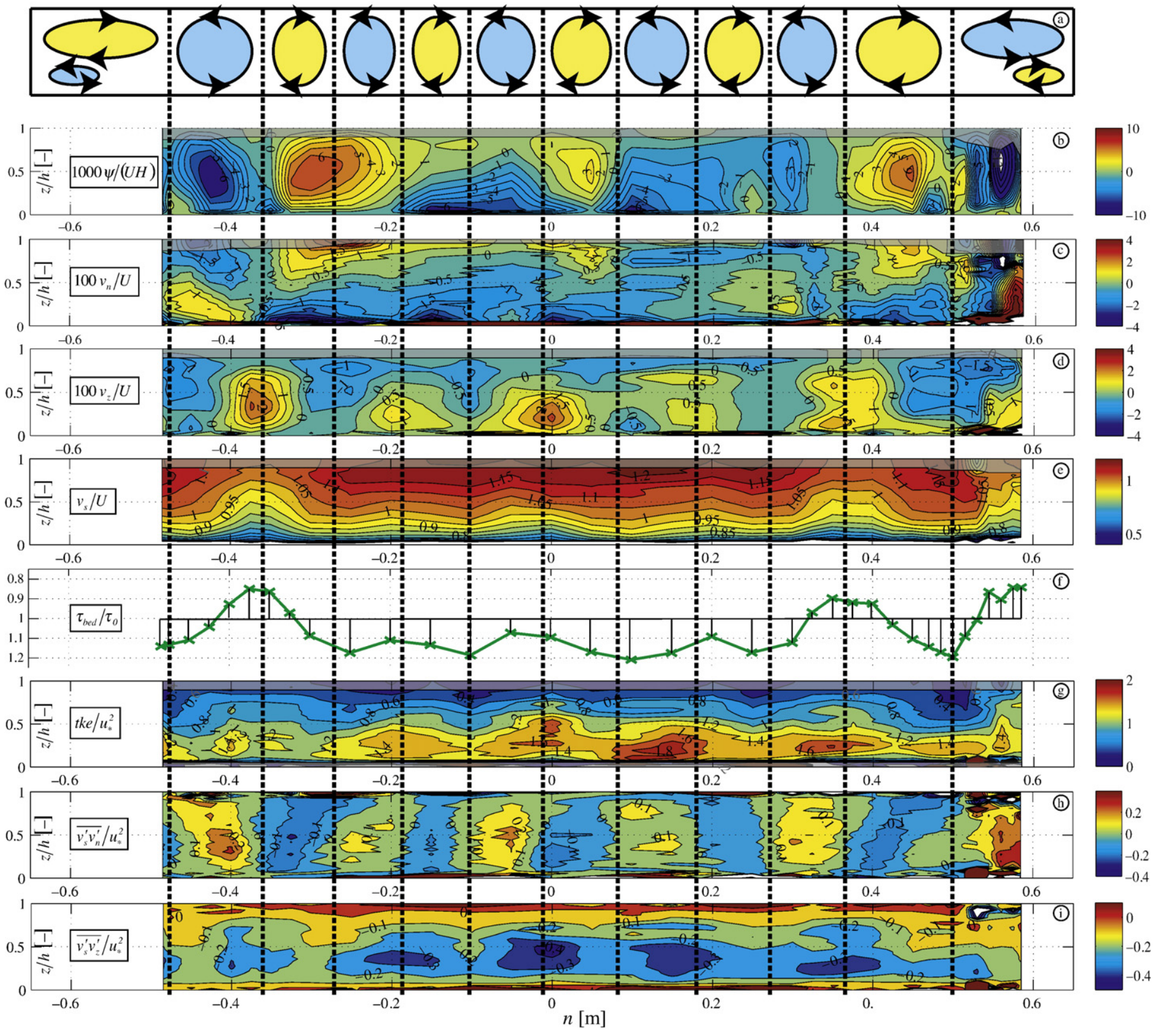

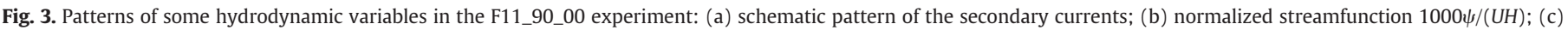

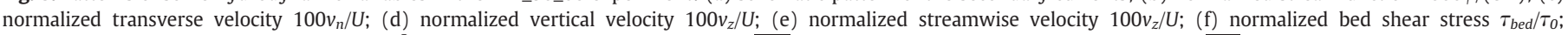

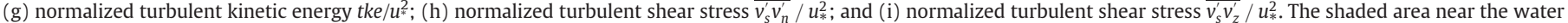
surface has been bridged by means of extrapolation from the measured values. Undistorted figure.

investigation of the influence of the bank inclination is extended to configurations with differentiated bed and bank roughness.

Figs. 6 and 7 show the patterns of the normalized streamfunction $1000 \psi /(U H)$ in the experiments with $45^{\circ}$ and $30^{\circ}$-inclined banks, respectively, for the three investigated roughness conditions of the bank. For comparison, they also include the experimental results of Tominaga et al. [29] in narrower smooth channels with bank inclinations of $44^{\circ}$ and $32^{\circ}$ respectively. The patterns of the seconday currents have been inferred from the simultaneous observations of the patterns of the major hydrodynamic variables, similar to Fig. 3. In all six investigated cases the secondary currents occur over the entire width of the cross-section and they do not weaken considerably with distance from the bank. Moreover they scale with the flow depth. The influence of the inclination and roughness of the left bank (at the right in the figures) is largely limited to the half-width of the cross-section, whereas flow patterns in the right half (at the left in the figures) of the cross-section adjacent to the smooth vertical bank are similar in all experiments. This observation suggests that the influence of bank configuration on the flow characteristics decreases with distance from that bank. In the experiments with $45^{\circ}$-inclined banks, the patterns of the secondary current cells in the central region of the cross-section ressemble the pattern found in the F16_90_00 experiment with vertical bank (cf. Fig. 4(a) and (b)). Six secondary current cells occur in the central region with horizontal bed and two cells occur in the region of the inclined bank. The experiments with a $30^{\circ}$-inclined bank also show two cells in the inclined bank region, but only four cells occur in the central region with horizontal bed. This may be attributable to the reduced width of the central region with horizontal bed. The strength of the secondary currents in the central part of the cross-section does not seem to depend considerably on the bank inclination. However, the experimental data suggests a slight strengthening with increasing roughness of the bank. 


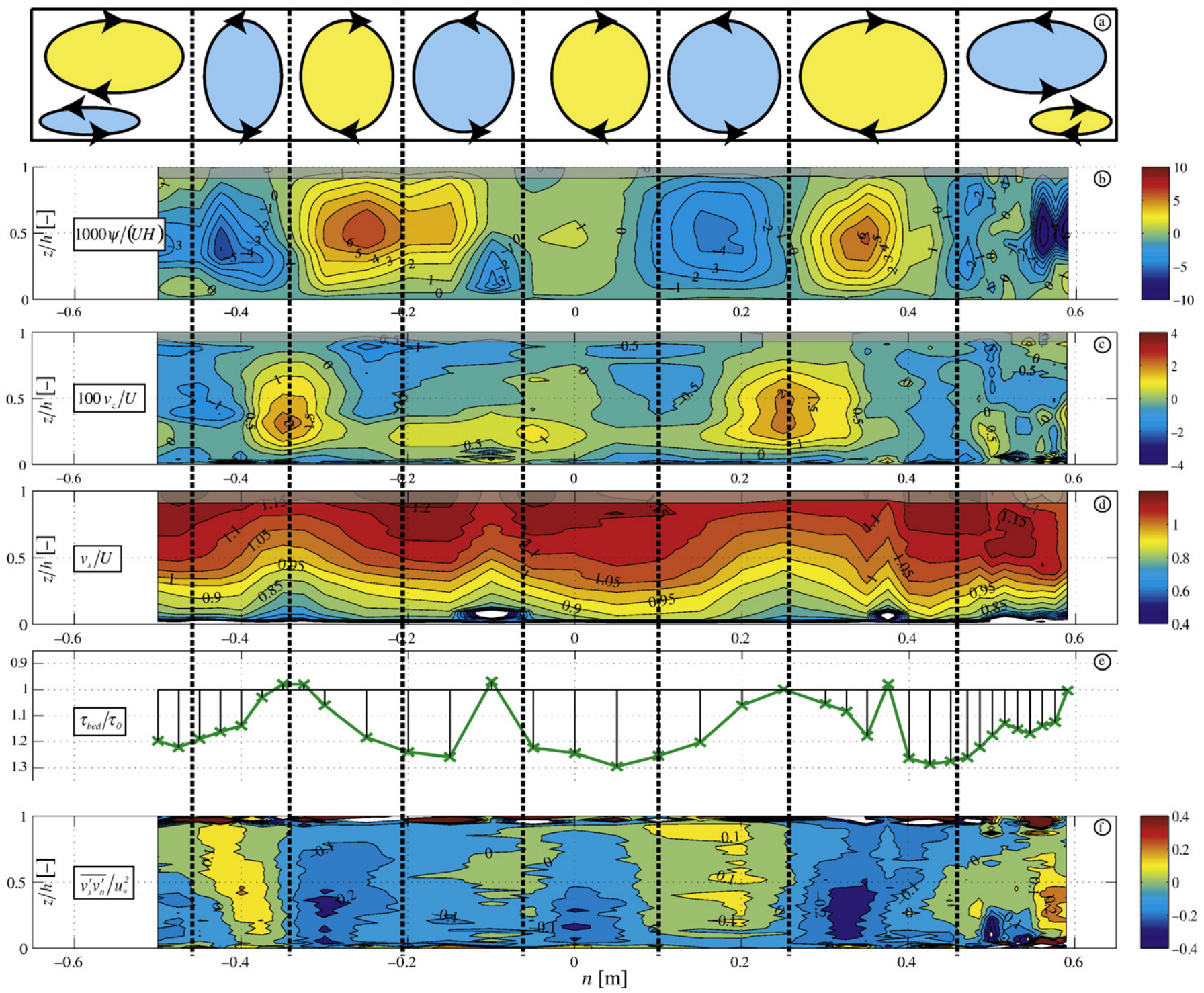

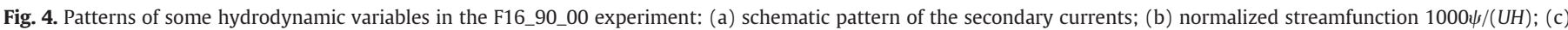

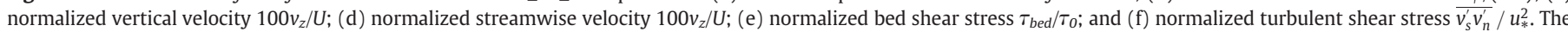
shaded area near the water surface has been bridged by means of extrapolation from the measured values. Undistorted figure.

Tominaga et al.'s [29] experiments in smooth trapezoidal channels revealed that inclining the bank generated an additional vortex (vortex $B$ in Fig. 6(d)) in the corner formed by the water surface and the bank. The surface-corner vortex $C$ and the bottom-corner vortex $A$ (cf. Fig. 6(d)) weakened and strengthened, respectively, with decreasing bank angle $\Theta_{\text {bank }}$. For bank angles less than $45^{\circ}$, the corner-bottom vortex $C$ was dominant and extended over the entire flow depth. Tominaga et al.'s [29] experiments on the influence of the roughness in rectangular channels revealed that the surface-corner vortex (vortex $C$ in Fig. 6(d)) was always the dominant near-bank vortex in open-channel flows. In channels with uniformly rough boundaries the near-bank vortices, especially the corner-bottom vortex (vortex $A$ in Fig. 6(d)), were weaker than in channels with uniformly smooth boundaries. Banks smoother than the bed weakened and reduced the bottom-corner vortex, whereas banks rougher than the bed strengthened and widened the near-bank vortices. Our experiments revealed that the patterns of the near-bank secondary currents were extremely sensitive to the inclination and roughness of the bank. However, our results generally comply with and confirm the tendencies indicated by Tominaga et al. [29]. The patterns of secondary currents in the trapezoidal channels with uniformly rough boundaries (Figs. 6(b) and 7(b)) ressembled those in channels with uniformly smooth boundaries (Figs. 6(d) and 7(d)). The nearbank vortices were weakened, however, and vortex $B$ was no longer discernable. The weakening of the near-bank vortices was more pronounced in the experiments with $30^{\circ}$-inclined bank than in those with the $45^{\circ}$-inclined bank. A bank that is smoother than the bed (Figs. 6(a) and 7(a)) was found to strengthen the surface-corner vortex $C$, which became the dominant vortex. A bank that is rougher than the bed (Figs. 6(c) and 7(c)) strengthened the near-bank vortices, especially vortex $B$.

Figs. 8 and 9 show the patterns of the normalized streamwise velocity $v_{s} / U$ and the normalized boundary shear stress $\tau / \tau_{0}$ in, respectively, the experiments with $45^{\circ}$-inclined and $30^{\circ}$-inclined banks for the three investigated roughness conditions of the bank. Aslo in the configurations with inclined banks, the patterns of the streamwise velocity and the boundary shear stress are in total synchronicity with those of the secondary currents. These inclined bank configurations have transverse variations in the streamwise velocity and the bed shear stress (Figs. 8 and 9) that are slightly larger than those found in configurations with vertical bank (Figs. 3, 4 and 5). Results for $30^{\circ}$ and $45^{\circ}$-inclined banks are 


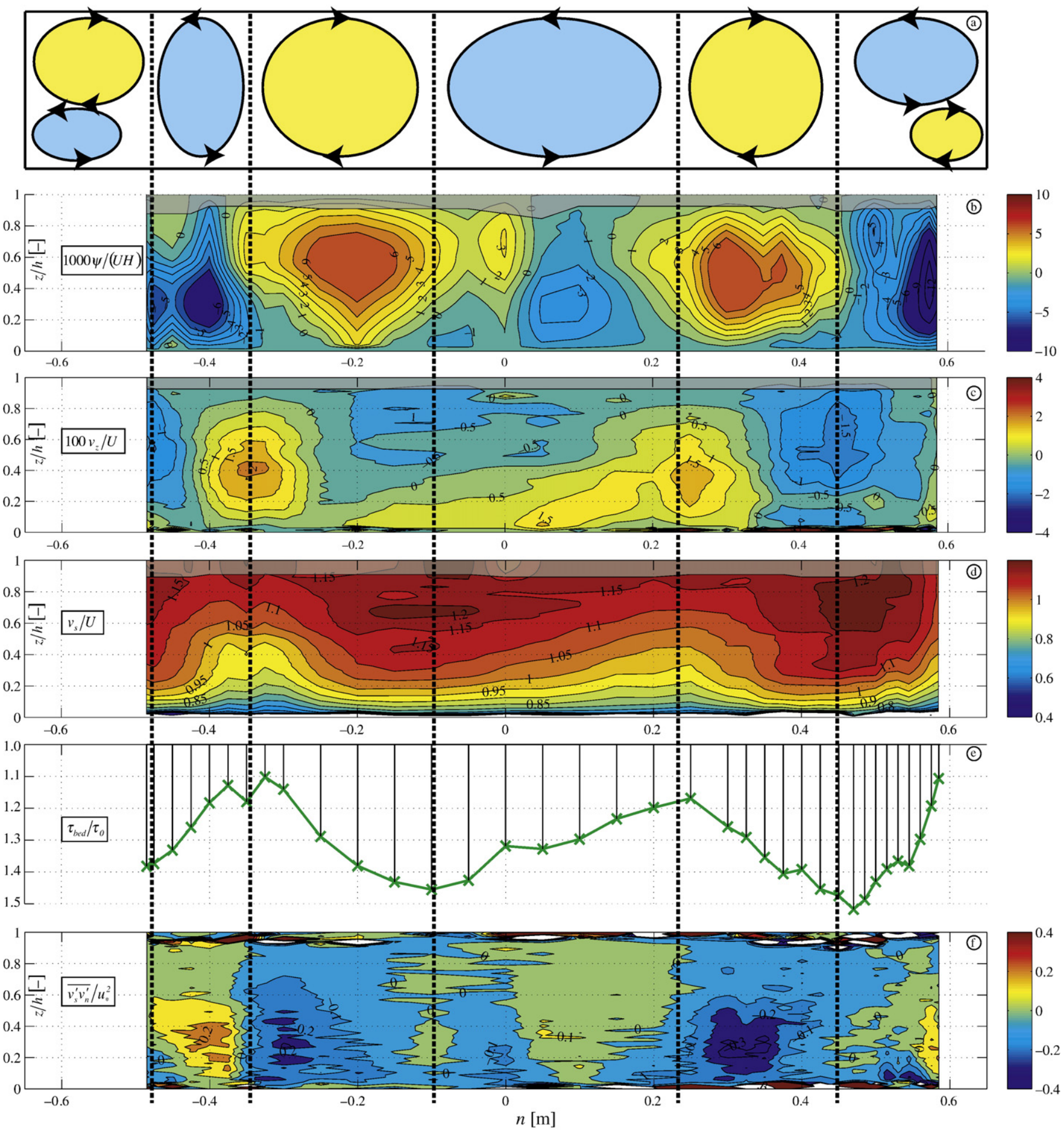

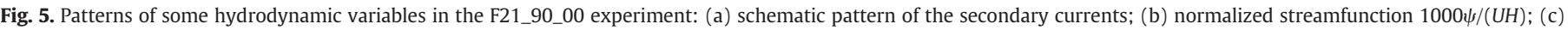

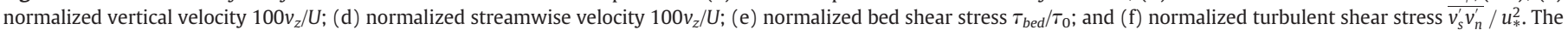
shaded area near the water surface has been bridged by means of extrapolation from the measured values. Undistorted figure.

similar. The near-bank secondary currents advect momentum away from the bank and cause a region of reduced bed shear stress in the vicinity of the bank. This region widens considerably when the roughness of the bank is increased, which is mainly due to the bottom-corner vortex $A$. The near-bank secondary currents advect momentum towards the lower part of the bank, which may endanger its stability. Increased roughness of the bank amplifies this effect; unlike smooth banks, for which the bank shear stress is approximately homogeneous, (Figs. 8a and 9a), rough banks exhibit a marked heterogeneity of stress with a pronounced maximum value near the toe of the bank (Figs. 8c and 9c). Roughening the bank causes a reduction in streamwise velocities in the vicinity of the bank, which results in a reduction of the bed shear stress. However, bank shear stress, on the contrary, increases considerably with increasing bank roughness due to the increase in the bank's friction coefficient (cf. Eq. (2)). 

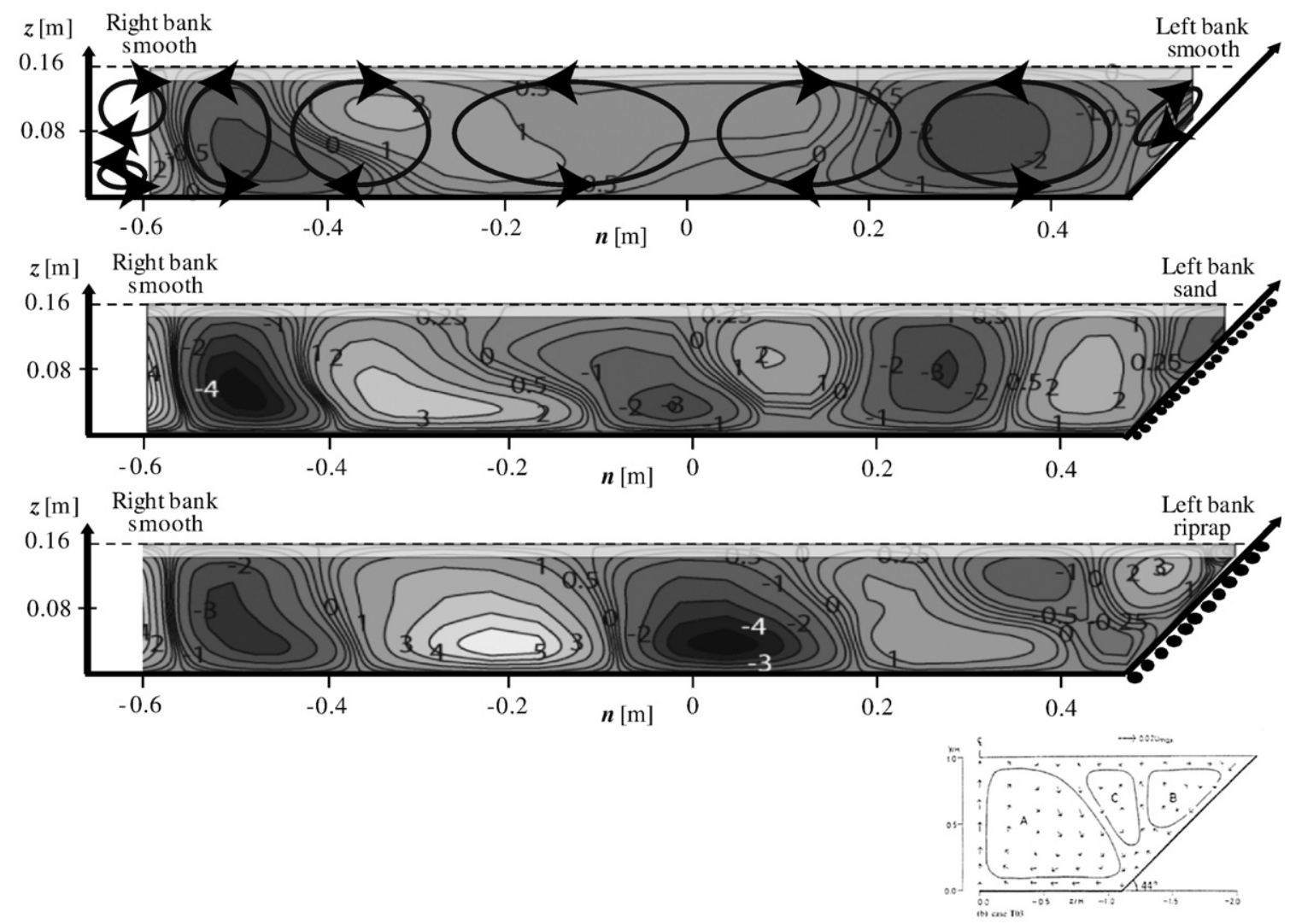

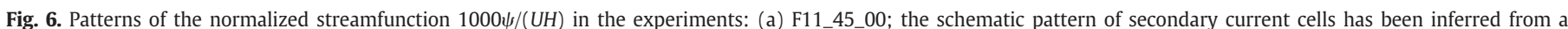

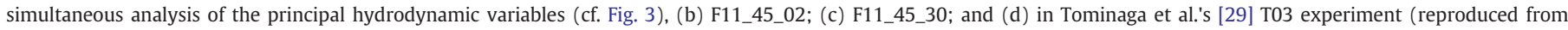
Tominaga et al.'s Fig. 3). The shaded area near the water surface has been bridged by means of extrapolation from the measured values. Undistorted figures.
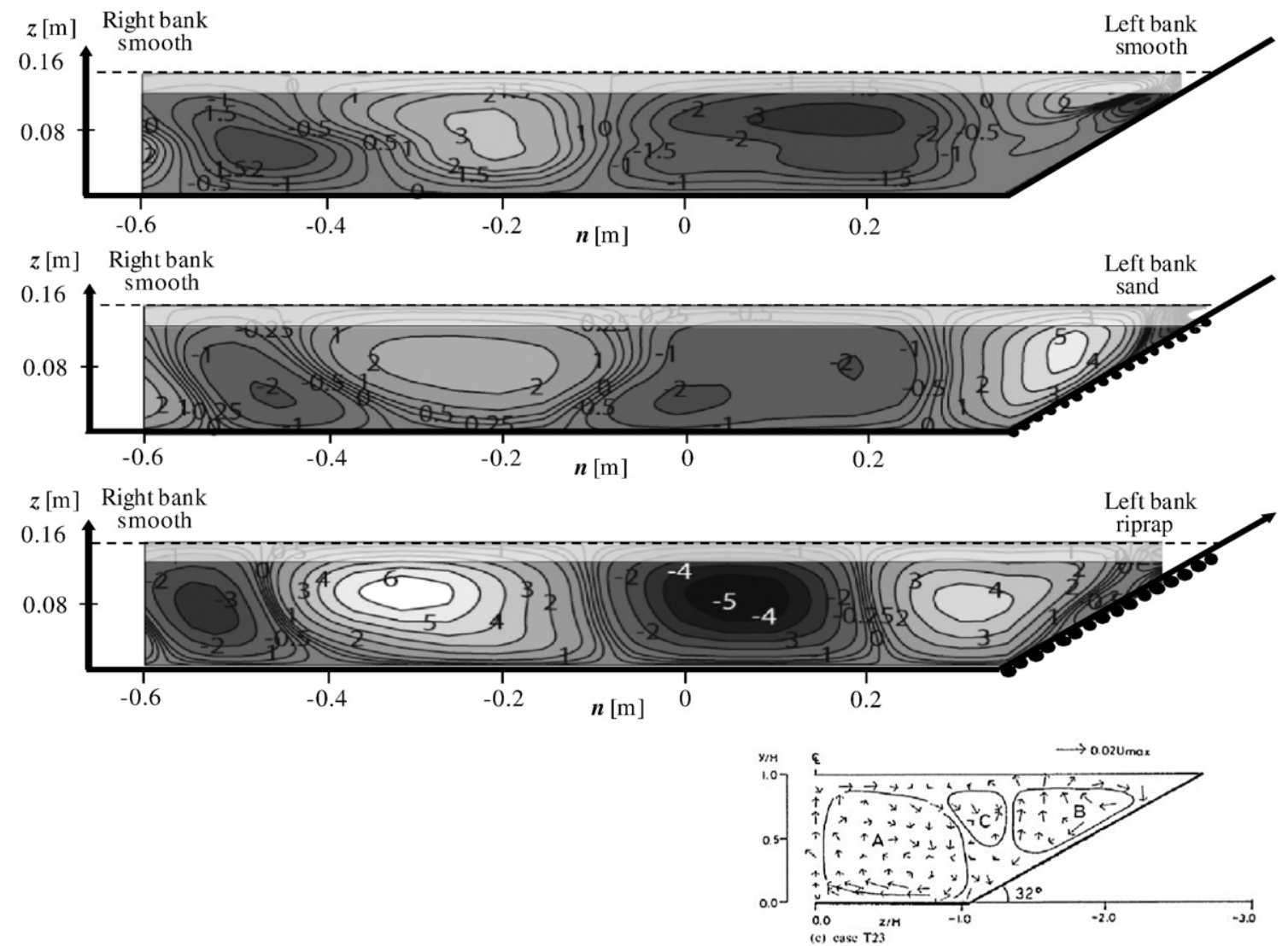

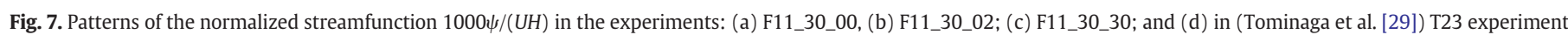
(reproduced from Tominaga et al.'s Fig. 3). The shaded area near the water surface has been bridged by means of extrapolation from the measured values. Undistorted figures. 

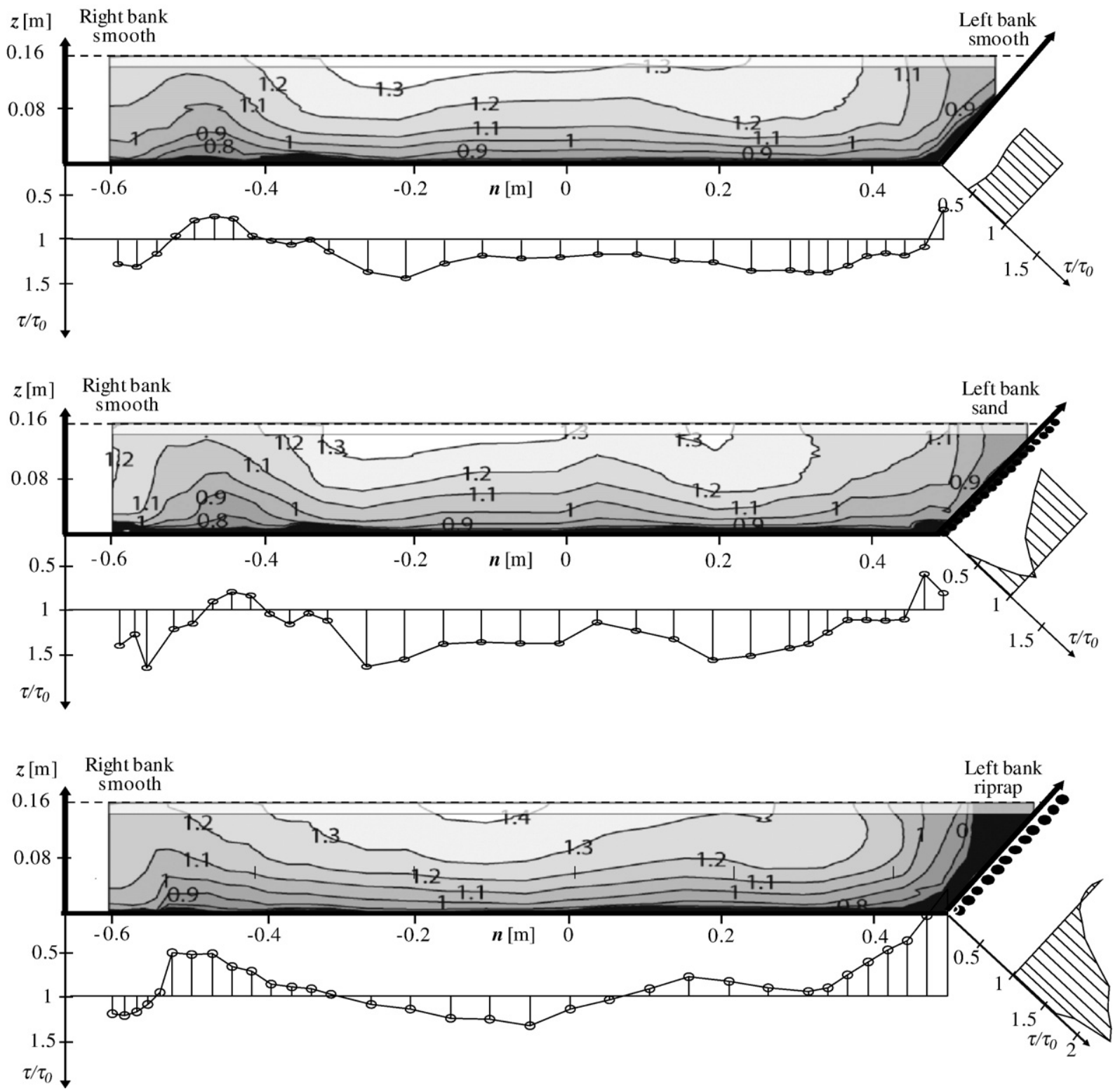

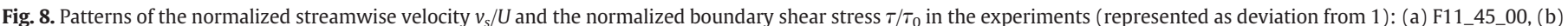
F11_45_02; and (c) F11_45_30. The shaded area near the water surface has been bridged by means of extrapolation from the measured values. Undistorted figures.

\section{Discussion}

The experimental data permits analysis of the conditions of occurrence of the secondary currents in the central part of shallow channels with fixed horizontal bed, as well as their generating mechanism. Moreover, these experiments provide hard data for analysis of the hypotheses of Rodrígues and Gárcia (2008, see Section 1). This data suggests that the generation of the secondary current cells in the central part of the cross-section is due to hydrodynamic instability related to the bed roughness. When secondary current cells exist, their characteristics seem to be largely independent of the bed roughness: they scale with the flow depth, reach maximum cross-stream velocities of less than $5 \%$ of the main velocity, and cause transverse oscillations in the streamwise velocity of about $\Delta U_{s} / U=10-15 \%$. These transverse velocity oscillations cause transverse oscillations in the bed shear stress of about $\Delta \tau_{\text {bed }} / \rho=0.2-$ $0.3 u_{*}^{2}$ and in the streamwise-transverse shear stress of about $\Delta \overline{v_{s}^{\prime} v_{n}^{\prime}}=0.4 u_{*}^{2}$ (Figs. 3 to 5 ). Scaling with the overall mean velocity yields $\Delta \tau_{\text {bed }} / \rho=0.2-0.3 C_{f, \text { bed }} U^{2}$ and $\Delta \overline{v_{s}^{\prime} v_{n}^{\prime}}=0.4 C_{f, b e d} U^{2}$ and indicates that the absolute values of the oscillations increase with the bed roughness. Nezu and Nakagawa's ([23], their Fig. 5.3) schematic representation of the hydrodynamic interactions that generate secondary currents clearly shows the importance of transverse oscillations in bed shear stress. According to Yang [36], the transverse oscillations in $\overline{v_{s}^{\prime} v_{n}^{\prime}}$ play a key role in the generation of secondary currents. He estimates the secondary current velocities as being proportional to:

$\frac{v_{n}}{U} \sim-\frac{\overline{v_{s}^{\prime} v_{n}^{\prime}}}{U^{2}} \approx v_{t} \frac{\partial v_{s} / \partial n}{U^{2}} \approx\left(\frac{\kappa}{6} u * H\right) \frac{\Delta U_{s} / H}{U^{2}} \approx \frac{\kappa}{6} C_{f}^{1 / 2} \frac{\Delta U_{s}}{U}$

Colombini [8] has shown analytically that transverse oscillations in the bed shear stress and turbulent shear stresses can sustain a stable pattern of secondary currents over the entire width of the river. In his analysis, however, sufficiently large transverse oscillations were only obtained by including the interaction between the flow and the sediment transport. Colombini [8] accounted for the effect of advective momentum transport by the secondary currents on the 

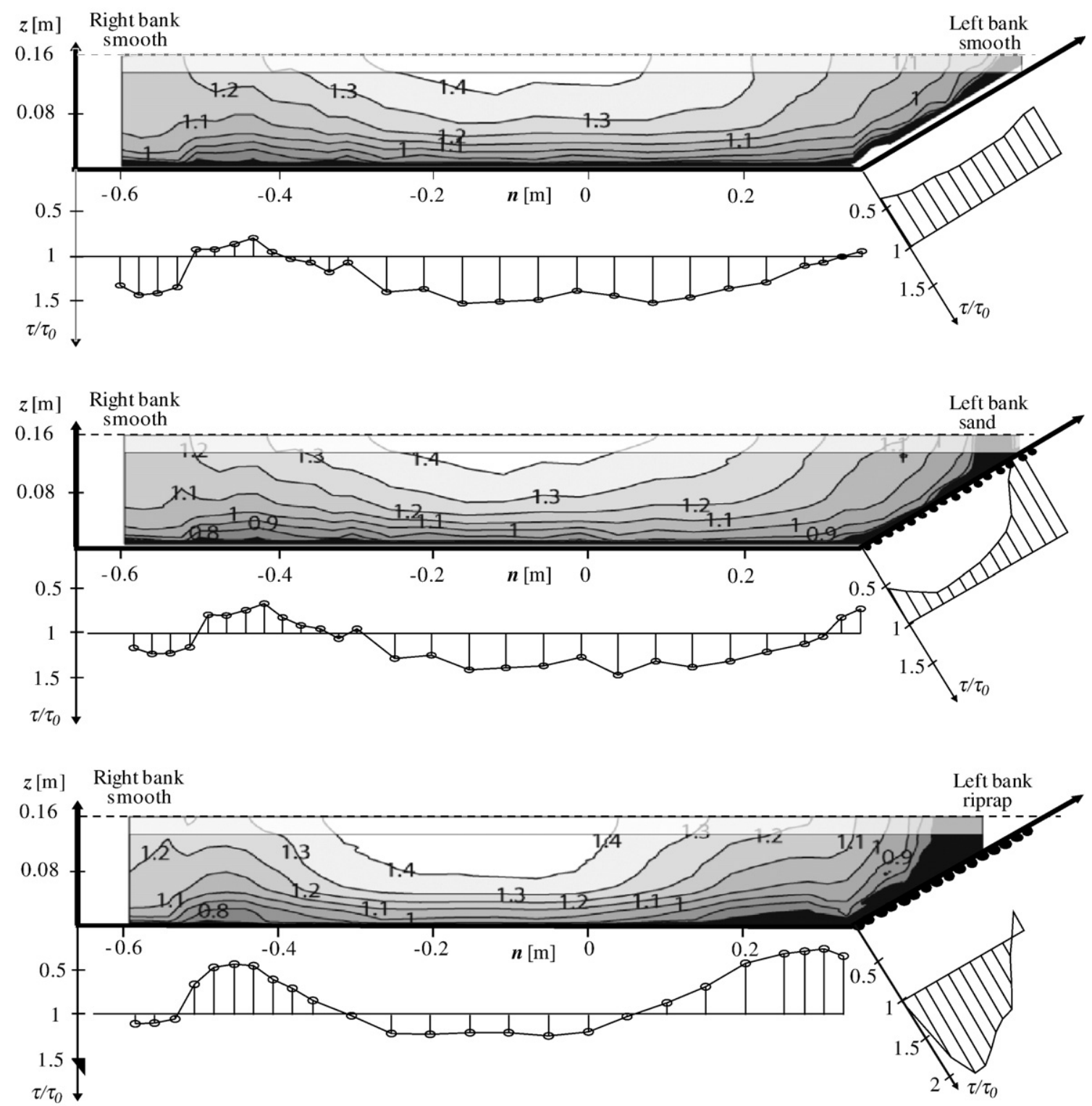

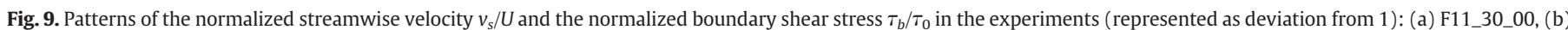
F11_30_02; and (c) F11_30_30. The shaded area near the water surface has been bridged by means of extrapolation from the measured values. Undistorted figures.

distribution of the bed shear stress. But he did not account for the modified vertical profiles of the velocity, which may cause transverse variations in the friction factor. In fact, for the same depth-averaged velocity, the near-bed velocity gradient is increased/decreased in zones of downflow/upflow [1], leading by definition to an increase/ decrease in the dimensionless Chézy friction coefficient as compared to purely 2D flow in the absence of secondary currents. Consideration of this phenomenon leads to the hypothesis that a stable pattern of secondary currents over the entire width can be sustained over a fixed horizontal bed. However, this stable pattern can only exist if the bed is rough enough to sufficiently deform the vertical velocity profiles. Such deformation provides the required transverse oscillations in the friction coefficient, bed shear stress and turbulent shear stresses. This purely hydrodynamic instability mechanism does not require any amplification (for example by imposed roughness variations or sediment transport) but does requires an external forcing to initiate the secondary currents. This external forcing is provided by the nearbank secondary currents. This hypothesis in line with Rodrígues and Gárcia's [27] assumption that the amplification of the surface-corner vortex due to the difference in roughness between the bank and the bed is at the origin of the pattern of secondary currents over the entire width. Although the bed in our reported experiments was not fully $\operatorname{rough}\left(R e_{*}=u * d / v \approx 50\right.$, which corresponds to the upper end of the transition region between smooth and rough turbulent boundary layer flow), the roughness was sufficient to generate a stable pattern of secondary currents over the entire width. Since the fully rough regime is encountered in most cases at field conditions in natural channels, they provide the required conditions for the generation of a stable pattern of secondary currents over the entire width, as well as the associated hydraulic, erosion and sedimentation variability.

As mentioned in the Introduction, the hydrodynamics of trapezoidal channels are far more complicated than those found in irregular geometries, such as the conditions encountered in natural or restored rivers. In such natural/restored conditions, the flow field is largely conditioned by the bathymetry and the planimetry $[3,31,32,37]$. Investigation of the flow variability due to the interaction between the main flow, the secondary currents and the turbulence characteristics in trapezoidal channels is relevant to various practical applications, several of which are discussed in the Introduction.

The generation of the near-bank secondary currents in openchannel flows has been attributed to the influence of the boundaries on turbulence characteristics $[4,23,26,29,38]$ and 
successfully simulated for cases with vertical banks by Naot and Rodi [21] and Naot [20]. The authors have not yet succeeded in resolving accurately the pattern of secondary currents in trapezoidal crosssections occuring over the entire width by means of the threedimensional large eddy simulation code reported by van Balen et al. [30], and have no knowledge of any other successful simulation. The reported experiments can constitute benchmark test cases that allow the improvement and validation of numerical models.

Although near-bank secondary currents are strongly influenced by the roughness and the inclination of the bank, the patterns in all experiments show some common features. Near-bank secondary currents reduce the bed shear stress in the vicinity of the bank, but increase it at a distance of about $2 \mathrm{H}$ from the bank. They cause a heterogeneous distribution of the bank shear stress, with a maximum value close to the toe of the bank. The stable design of channels requires knowledge of the maximum bed and bank shear stresses. Table 3 compares the measured maximum bed and bank shear stresses found in the trapezoidal cross-section experiments with predictions based on commonly used empirical methods. Chow's ([7], Fig. 1) boundary shear stress distribution is based on experiments in smooth trapezoidal laboratory flumes (see Fig. 1). Knight et al. [16,17] developed empirical estimators based on a series of laboratory experiments in trapezoidal channels with homogeneous boundary roughness as well as roughened banks. These estimators are given by:

$$
\begin{aligned}
& \left(\frac{\tau_{\text {bed }}}{\tau_{0}}\right)_{\max }=\left(1-0.01 S F_{\text {bank }}\right)\left(0.8+\left(\frac{P_{\text {bed }}}{P_{\text {bank }}}\right)^{-0.35}\right) \\
& \left(\frac{\tau_{\text {bank }}}{\tau_{0}}\right)_{\max }=0.01 S F_{\text {bank }}\left(2.37+\left(\frac{P_{\text {bed }}}{P_{\text {bank }}}\right)^{0.85}\right) \\
& S F_{\text {bank }}=e^{\alpha} \\
& \alpha=-3.23 \log \left(\frac{P_{\text {bed }}}{P_{\text {bank }} C_{2}}+1\right)+4.6052 \\
& C_{2}=1.5\left(\frac{k_{s, \text { bank }}}{k_{s, \text { bed }}}\right)^{0.2115} .
\end{aligned}
$$

As expected, Chow's [7] boundary shear stress distribution predicts well the behavior of configurations with homogeneous boundary roughness. For cases with heterogeneous boundary roughness, the method satisfactorily predicts the maximum bed shear stress, but fails to predict the maximum bank shear stress. Knight et al.'s $[16,17]$ method provides valuable engineering estimates for all configurations, although the maximum bed shear stresses are somewhat underestimated. Knight et al.'s technique is especially

\begin{tabular}{|c|c|c|c|c|}
\hline & \multicolumn{2}{|c|}{$\begin{array}{l}\text { Maximum normalized bank } \\
\text { shear stress, }\left(\tau_{\text {bank }} / \tau_{0}\right)_{\max }\end{array}$} & \multicolumn{2}{|c|}{$\begin{array}{l}\text { Maximum normalized bed } \\
\text { shear stress, }\left(\tau_{\text {bed }} / \tau_{0}\right)_{\max }\end{array}$} \\
\hline & $30^{\circ}$ & $45^{\circ}$ & $30^{\circ}$ & $45^{\circ}$ \\
\hline $\begin{array}{c}\text { Smooth bank } \\
\text { F16_30_00 } \\
\text { F16_45_00 }\end{array}$ & $0.5[1.0](0.5)$ & $0.5[1.0](0.5)$ & $1.4[1.3](1.3)$ & $1.3[1.3](1.3)$ \\
\hline $\begin{array}{l}\text { Homogeneous } \\
\text { boundary } \\
\text { roughness } \\
\text { F16_30_02 } \\
\text { F16_45_02 }\end{array}$ & $0.9[1.0](1.1)$ & $0.9[1.0](1.1)$ & $1.3[1.3](1.2)$ & $1.3[1.3](1.2)$ \\
\hline $\begin{array}{l}\text { Roughened bank } \\
\text { F16_30_30 } \\
\text { F16_45_30 }\end{array}$ & $1.8[1.0](1.8)$ & $1.8[1.0](1.7)$ & $1.2[1.3](0.9)$ & $1.2[1.3](1.0)$ \\
\hline
\end{tabular}

\section{Table 3}

Comparison of measured maximum normalized bank and bed shear stresses in the experiments with trapezoidal cross-section to predictions according to the methods of Chow [7] and Knight et al. [17], indicated by values between square and round brackets, respectively. accurate in predicting the maximum bank shear stresses, even for cases with smooth banks. It should be noted, however, that Knight's method has no general validity and can only reliably be applied within the parameter range adopted for its derivation, with the most important ranges being those of the aspect ratio $\mathrm{B} / \mathrm{H}$ and the boundary roughness.

\section{Conclusions}

Secondary currents and the flow variability that they induce were measured in straight laboratory flumes with fixed boundaries by means of an Acoustic Doppler Velocity Profiler that measured the three-dimensional velocity vector with high spatial and temporal resolution. Through investigation of shallowness, roughness characteristics of the bed and the bank and the inclination of the bank, these experiments broaden and complete the parameter space covered in previous investigations.

Secondary currents occured over the entire width in all experiments. They scale with the flow depth and show velocities of about $2 \%$ of the streamwise velocity. These findings are consistent with the experimental findings of Tominaga et al. [29], Nezu et al. [25], Albayrak [1] and Rodrígues and Gárcia [27]. However, these findings contradict the widespread perception that secondary currents die out at a distance of 2.5 times the flow depth from the bank, a perception largely based on laboratory experiments in smooth air ducts by Nezu et al. [24]. Our reported results indicate that hydrodynamic instability is at the basis of these different patterns: a stable pattern of secondary currents over the entire width can only be sustained over a fixed horizontal bed if the roughness is sufficient to provide the required transverse oscillations in the bed shear stress and the turbulent shear stresses. The hydrodynamic instability is driven by the near-bank secondary currents, which are known to be turbulence-induced. The conditions prevailing in natural rivers do provide the required roughness for the generation of the secondary currents over the entire river's width.

The pattern of near-bank secondary currents depends on the inclination and the roughness of the bank. In all configurations, however, they result in a reduction of the bed shear stress in the vicinity of the bank and a heterogeneous bank shear stress that reaches a maximum close to the toe of the bank. Advective momentum transport by the secondary currents causes transverse variability of the flow consistent with previous results: about $10-15 \%$ in the streamwise velocities and $0.2 u^{2}-0.3 u^{2}$ in the bed shear stress. These variations are insufficient to provide the flow variability required in river restoration projects, but have to be accounted for in the design of stable channels. Because numerical models are not yet able to successfully simulate the pattern of secondary currents and the induced flow variability, engineering applications must rely on empirical methods. The commonly applied boundary shear stress distribution of Chow [7] satisfactorily estimates the bed shear stress but fails to estimate the bank shear stress. Knight et al.'s [16,17] method provides satisfactory estimates for the bank and bed shear stresses within the range of experimental conditions adopted for its derivation.

The interaction between the main flow, secondary currents and turbulence characteristics is known to be far more subtle and complicated in trapezoidal channels than in irregular geometries such as those encountered in natural or restored rivers. The reported experiments can constitute benchmark testcases that allow the improvement and validation of numerical models.

\section{Notations}

$B \quad$ Average of the width at the bed and at the water surface

$C_{f}=g R_{h} E_{S} / U^{2}$ Dimensionless Chézy friction coefficient

$E_{\mathrm{s}} \quad$ Energy slope

$\mathrm{Fr}=U /(\mathrm{gH})^{1 / 2}$ Froude number 


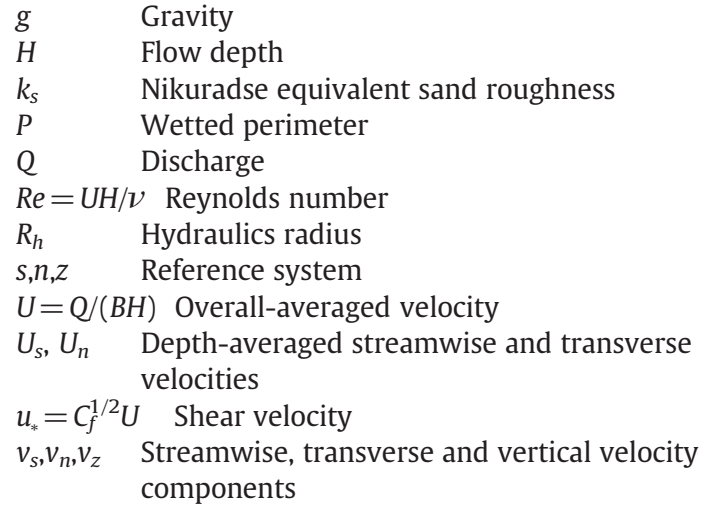

Greek symbols

$\Theta_{\text {bank }} \quad$ Inclination of the bank with respect to a horizontal bed

$\kappa \quad$ Von Kármán's constant

$\nu_{t} \quad$ Eddy viscosity

$\rho \quad$ Water density

$\tau \quad$ Boundary shear stress

$\tau_{0}=\rho g R_{h} E_{s}$ Averaged shear stress in the cross-section

$\psi \quad$ Streamfunction

\section{Acknowledgements}

This research was funded by the Swiss National Science Foundation under grants SNF 20020-103932, SNF 200020-119835/1. The first author was partially supported by the Chinese Academy of Sciences fellowship for young international scientists under Grant No. 2009YA1-2.

\section{References}

[1] Albayrak, I. (2008). "An experimental study of coherent structures, secondary currents and surface boils and their interrelation in open-channel flow". Ph.D. thesis no. 4112, Ecole Polytechnique Fédérale Lausanne, Switzerland.

[2] Batcheleor GK. An introduction to fluid dynamics. Cambridge, U.K.: Cambridge Univ. press; 1967.

[3] Blanckaert, K. (2010), Topographic steering, flow recirculation, velocity redistribution, and bed topography in sharp meander bends. Water Resour. Res., 46, W09506, doi:10.1029/2009WR008303.

[4] Blanckaert K, de Vriend HJ. Secondary flow in sharp open-channel bends. J Fluid Mech 2004;498:353-80.

[5] Blanckaert K, Graf WH. Experiments on flow in an open-channel bend. Mean flow and turbulence. J Hydraul Eng 2001;127(10):835-47.

[6] Blanckaert $K$, Lemmin U. Means of noise reduction in acoustic turbulence measurements. J Hydraul Res 2006;44(1):3-17.

[7] Chow VT. Open-channel hydraulics. New York, N.Y.: McGraw-Hill Book Co.; 1959

[8] Colombini M. Turbulence driven secondary flows and the formation of sand ridges. J Fluid Mech 1993;254:701-19.

[9] Duarte, A. (2008). "An experimental study on main flow, secondary flow and turbulence in open-channel bends with emphasis on their interaction with the outer-bank geometry". PhD thesis no 4227, Ecole Polytechnique Fédérale Lausanne, Switzerland.
[10] Hurther D, Lemmin U. A constant beamwidth transducer for three-dimensional Doppler profile measurements in open channel flow. Meas Sci Technol 1998;9 (10):1706-14.

[11] Ikeda S. Self-formed straight channels in sandy beds. J Hydraul Div 1981;107: 389-406.

[12] Karcz I. Secondary currents and the configuration of a natural stream bed. J Geophys Res 1966;71:3109-16.

[13] Kinoshita R. An analysis of the movement of flood waters by aerial photography, concerning characteristics of turbulence and surface flow. Photogr Surv 1967;6: 1-17 (in Japanese).

[14] Knight DW, Patel J. Boundary shear in smooth rectangular ducts. J Hydraul Eng 1985;111(1):29-47.

[15] Knight DW, Demetriou JD, Hamed ME. Boundary shear in smooth rectangular channel. J Hydraul Eng 1984;110(4):405-22.

[16] Knight DW, Alhamid AAI, Yuen KWH. Boundary shear in differentially roughened trapezoidal channels. In: Falconer RA, Shiono K, Mathew RGS, editors. Hydraulics and environmental modeling. Estuarine and river waters. Ashgate Publishing; 1992. p. 3-14. Ch. 1.

[17] Knight DW, Alhamid AAI, Yuen KWH. Boundary shear stress distributions in openchannel flow. In: Beven K, Chatwin P, Millbank J, editors. Physical mechanisms of mixing and transport in the environment. J. Wiley; 1994. p. 51-87. Ch. 4.

[18] Lemmin U, Rolland T. Acoustic velocity profiler for laboratory and field studies. ] Hydraul Eng ASCE 1997;123(12):1089-98.

[19] McLelland SJ, Ashworth PJ, Best JL, Livesey JR. Turbulence and secondary flow over sediment stripes in weakly bimodal bed material. J Hydraul Eng 1999;125(5): 463-73.

[20] Naot D. Response of channel flow to roughness heterogeneity. J Hydraul Eng 1984;110(11):1568-87.

[21] Naot D, Rodi W. Calculation of secondary currents in channel flow. J Hydraul Div ASCE 1982;108(8):948-68.

[22] Nezu I, Nakagawa H. Cellular secondary currents in straight conduit. J Hydraul Eng 1984;110(2):173-93.

[23] Nezu I, Nakagawa H. Turbulence in open-channel flows. Rotterdam, The Netherlands: Balkema; 1993.

[24] Nezu I, Nakagawa H, Tominaga A. Secondary currents in a straight channel flow and the relation to its aspect ratio. Turbulent shear flows 4. Springer-Verlag; 1985. p. 246-60.

[25] Nezu I, Tominaga A, Nakagawa H. Field measurements of secondary currents in straight rivers. J Hydraul Eng 1993;119(5):598-614.

[26] Prandtl L. Führer durch die Strömungslehre. Braunschweig: Vieweg; 1942.

[27] Rodrígues JF, Gárcia MH. Laboratory measurements of 3-D flow patterns and turbulence in straight open channel with rough bed. J Hydraul Res 2008;46(4): 454-65.

[28] Studerus, X. (1982). "Sekundarstromungen im offenen Gerinne uber rauhen Langsstreifen". Ph.D thesis, ETHZ, Zurich, Switzerland.

[29] Tominaga A, Nezu I, Ezaki K, Nakagawa H. Three-dimensional turbulent structure in straight open-channel flows. J Hydraul Res 1989;27:149-73.

[30] Van Balen W, Uijttewaal WSJ, Blanckaert K. Large-eddy simulation of a mildly curved open-channel flow. J Fluid Mech 2009;630:413-42.

[31] Van Balen W, Blanckaert K, Uijttewaal WSJ. Analysis of the role of turbulence in curved open-channel flow at different water depths by means of experiments, LES and RANS. J Turbul 2010;11, doi:10.1080/14685241003789404 Art. no. N 12, first published on: 23 April 2010.

[32] Van Balen W, Uijttewaal WS], Blanckaert K. "Large-eddy simulation of a curved open-channel flow over topography". Physics of Fluids 22, 075108, doi: 10.1063/1.3459152.

[33] Vanoni VA. Transportation of suspended sediment by water. Trans ASCE 1946;111: 67-133.

[34] Wang ZQ Cheng NS. Secondary flows over artificial bed strip. Adv Water Resour 2005;28(5):441-50.

[35] Wang ZQ Cheng NS. Time-mean structure of secondary flows in open channel with longitudinal bedforms. Adv Water Resour 2006;29(11):1634-49.

[36] Yang S-Q. Mechanism for initiating secondary currents in channel flows. Can J Civ Eng 2009;36:1506-16.

[37] Zeng J, Constantinescu G, Blanckaert K, Weber L. Flow and bathymetry in sharp open-channel bends: experiments and predictions. Water Resour Res 2008;44: W09401, doi:10.1029/2007WR006303.

[38] Einstein HA, Li H. Secondary currents in straight channels. Trans AGU 1958;39: 1085-8. 